\title{
As práticas culturais de infância no processo de alfabetização e letramento no Ensino Fundamental I
}

\section{Andrêssa Silva Rodrigues ${ }^{1}$ e Sânzio Danilo de Oliveira Santos ${ }^{2}$}

\author{
1 Graduada em Pedagogia pela Universidade Estadual do Sudoeste da Bahia. \\ E-mail: contatorodrigues@live.com 9 http://lattes.cnpq.br/6173525745610774 \\ 2 Graduado em Química Licenciatura pela Universidade Estadual do Sudoeste da Bahia. \\ E-mail: sanziodanilo@gmail.com 9 http://lattes.cnpq.br/7835374594685682
}

RESUMO: O presente artigo focaliza-se na reflexão do Estágio Supervisionado no Ensino Fundamental I - Séries Iniciais acerca do enfoque na alfabetização e letramento a partir da prática cultural da infância: peteca. Neste sentido, buscou-se compreender de que forma as práticas culturais beneficiam a prática docente na alfabetização? Como o jogo/brincadeira com a peteca possibilita apreensão da escrita e leitura? Como as práticas culturais possibilitam gosto pela leitura e apreensão de conceitos? O artigo foi desenvolvido por meio do autoestudo sobre a experiência do estágio, num movimento dialético entre prática-teoria que nos possibilitou ter mais clareza sobre a ação docente. O estágio foi realizado em uma escola Municipal, da cidade de Itapetinga, na Bahia, com o projeto de intervenção "Processo de alfabetização e letramento a partir de uma prática cultural da infância: peteca" que durou duas semanas de regência. A reflexão apresenta as estratégias didáticas para alfabetizar a partir de práticas culturais presentes no cotidiano das crianças, explanando a construção do processo de leitura e escrita a partir da ludicidade, tornando-as autoras do seu processo de aprendizagem.

Palavras-chave: Ensino Fundamental, Prática Cultural, Alfabetização, Peteca.

\section{The cultural practices of childhood in the process of literacy and literacy in elementary school I}

ABSTRACT: This article focuses on the reflection of the Supervised Internship in Basic Education I - Initial Series about the focus on literacy and literacy from the cultural practice of childhood: peteca. In this sense, we tried to understand how cultural practices benefit the teaching practice in literacy? How does the game / joke with the shuttle enable apprehension of writing and reading? How do cultural practices enable a taste for reading and apprehending concepts? The article was developed through self-study on the experience of the stage, in a dialectical movement between practice-theory that allowed us to have more clarity about the teaching activity. The internship was held at a municipal school in the city of Itapetinga, Bahia, with the intervention project "Literacy process and literacy from a cultural practice of childhood: peteca", which lasted two weeks of regency. The reflection presents the didactic strategies to alphabetize from the cultural practices present in children's daily life, explaining the construction of the process of reading and writing from playfulness, making them authors of their learning process.

Keywords: Elementary Education, Cultural Practice, Literacy, Shuttlecock.

\section{INTRODUÇÃO}

A definição de "alfabetização" vai além do ato de ensinar a ler e a escrever, envolve sobretudo, o letramento. A prática de aprender a apropriação da escrita e da leitura por meio de contextos interligados com os conhecimentos prévios dos discentes 
para que seja significativo, sendo ressaltados nesse processo os níveis que os sujeitos passariam, que podemos constatar: présilábico, no qual o sujeito não tinha a percepção de que a escrita concebe os segmentos sonoros da palavra, até as etapas silábico quando a criança percebe a lógica da escrita e silábico-alfabético quando a criança percebe que há um funcionamento da escrita, compreendendo que as sílabas podem ser representadas por uma ou mais letras.

No processo de alfabetização, a criança deve estar entrelaçada nos procedimentos que envolvem a leitura e escrita e quando este processo é inserido a partir de algo que é vivido e construído pelos alunos, fica mais significativo. Dessa forma, nosso estágio propôs trabalhar na alfabetização a partir de uma prática cultural da infância que requer o uso metodológico da ludicidade, e este artigo busca: compreender e analisar a prática cultural como método para a apropriação da escrita e letramento, num movimento dialético entre prática-teoria que nos possibilitou ter mais clareza sobre a ação docente.

Assim, para analisar a prática docente e o processo de alfabetização e letramento a partir da prática cultural, fez-se definir um recurso metodológico, por meio do auto estudo, conforme afirma Souza et al (2014, p. 298) “O auto - estudo sobre si próprio visa analisar as preocupações, os dilemas e as questões do ensino sobre o ensino, consistindo numa resposta individual para compreender melhor a prática". O estágio supervisionado foi desenvolvido numa Escola Municipal na cidade de Itapetinga, na Bahia, em uma turma do 10 ano do ensino fundamental I, com funcionamento matutino e vespertino, sendo realizado o estágio pelo turno da tarde, das 14:00h às 17:30h, com 30 (trinta) alunos na turma.

No período de 01 a 12 de junho de 2015 foi desenvolvido o projeto "processo de alfabetização e letramento a partir da prática cultural da infância: peteca", portanto, a análise e as atividades aplicadas durante o projeto constituíram as ferramentas para a reflexão do estudo.

Para tanto, a reflexão sobre o estágio se constitui através da crítica teórica, baseada em autores e teóricos, como: Abreu et al. (2000), Lima (2009), Santos et al. (2007) e Sarmento (2004). Nos tópicos seguintes será apresentado o conceito de alfabetização e letramento a partir das culturas infantis, percebendo a criança como ator social da construção de seu desenvolvimento, trazendo o embasamento da peteca como prática cultural na infância e por último a análise didática acerca das contribuições da prática cultural: peteca.

\section{CONCEITUANDO ALFABETIZAÇÃO E LE- TRAMENTO A PARTIR DAS CULTURAS IN- FANTIS}

Este tópico abarca o conceito de alfabetização e letramento a partir das culturas elaboradas pelas crianças que é tido como cultura de pares, que são um conjunto de atividades ou rotinas que as crianças produzem na interação com seus parceiros ou grupos, por isso apresenta essa denominação.

Primeiramente, precisamos compreender o sentido de alfabetização que se estabelece no processo de propor ao sujeito apreensão de sua própria língua materna, não se restringindo à apropriação dos códigos de forma descontextualizada, mas compreender em seu dia-a-dia que ele já se 
encontra inserido no mundo social da escrita e leitura de forma harmônica, aproximando-se desde cedo da leitura, para que o aprendiz consiga fazer uso social de leitura e escrita nos diversos contextos sociais.

A alfabetização é uma aprendizagem mais ampla e complexa do que o "bê-a-bá". Esta concepção ampliada do conteúdo da alfabetização acabou por levar a uma orientação pedagógica na qual, além de aprender sobre as letras, os alunos aprendem sobre os diversos usos e as formas da língua que existem num mundo onde a escrita é um meio essencial de comunicação (ABREU et al, 2000, p. 4).

Para que o aprendiz compreenda sua língua materna como mecanismo para escrever em português, é necessário que ocorra a comunicação através de uma unidade funcional da língua - o texto. Abreu et al. (2000), afirma que o contato com a prática de leitura é essencial para que a criança perceba a funcionalidade da leitura e escrita, por isso é importante os momentos de leitura na sala de aula, levando em consideração que não são todos os alunos que tem pais presentes no seu desenvolvimento, por isso a responsabilidade dos professores de oferecerem e inserirem seus alunos nesse contexto. Percebendo a criança como construtora social, pois se ela convive em um ambiente que há valorização da leitura, ela irá reproduzir nas escolas e nas outras instâncias que participa, pois será uma habito normatizado em seu cotidiano.

As rotinas culturais que as crianças produzem em seu cotidiano possibilitam-nas entender as variáveis do mundo adulto, como os aspectos interligados aos papeis sociais, referente a gênero e classe social. Ou seja, as crianças reproduzem o que os adultos exercem em sua rotina, elas inter- nalizam um padrão de rotina cultural e seus aspectos principais do meio social, não se restringindo a internalização dessa cultura, mas contribuindo ativamente para a produção cultural.

\begin{abstract}
As culturas infantis são as culturas produzidas pelas crianças, nos seus fazeres da vida cotidiana, sozinhas ou em interlocução com outras crianças, com a presença ou não dos adultos, no interior de uma cultura heterogênea e abrangente. As crianças estão imersas em várias culturas e singularizam essas informações culturais em seus pequenos grupos de convívio e também individualmente (BARBOSA, 2014, p. 657).
\end{abstract}

As crianças já aprendem isso desde muito cedo, pelo convívio e interação social, elas percebem como é constituído os aparatos sociais, trazendo esses aspectos para seus grupos ou parceiros. Barbosa (2014, p. 658) acrescenta que "as crianças são atores sociais, pois são capazes de realizar interações e de dar sentido às suas ações, como todos os seres humanos, em suas diversidades".

Compreender essa percepção e concepção de criança e infância, facilita de tal modo o processo de letramento que se apresenta como os códigos ou sinais da linguagem falada. Para Geiger (2011, p. 539) o letramento significa ter a "[...] capacidade de e disposição para, uma vez dominada a técnica de ler e escrever, usá-la para assimilar e transmitir informação, conhecimento etc.". Através do letramento os discentes aprendem a compreender o que escrevem e leem.

Portanto, além do conhecimento sobre as letras, o professor precisa ensinar a seus alunos, ao mesmo tempo, a linguagem que se usa para escrever os diferentes gêneros. $\mathrm{E}$ a 
forma de ensinar isso é trazendo para dentro da sala de aula a diversidade textual que existe fora. É lendo para eles - em situações onde essa leitura faça sentido - os mais variados textos (ABREU et al, 2000, p. 5).

O contato com o mundo letrado é mais necessário para as crianças que apresentam maior dificuldade para alguém ler um livro e inserir este mundo da leitura em seu cotidiano, deixando a responsabilidade do incentivo à leitura para o professor propiciar as crianças a terem acesso ao conhecimento letrado. Abreu et al. (2000), chama atenção no que se refere ao debate com os aprendizes, de ensinar a ler e a escrever para quê? O que é escrita? São questionamentos que trará aos discentes a percepção do porquê eles devem aprender, assim verá mais sentido em estar na escola e do que buscam saber.

Ensinar a ler e a escrever é um processo sistemático e se for feito de forma contextualizada com a vivência dos discentes, cativam-nos de forma a querer desenvolver-se, se vendo como atores sociais de seu desenvolvimento pessoal e social. Para assim, refletir sobre o que buscam aprender e do que mais sentem prazer, sendo relevante ressaltar as (re)produções culturais que se encontram nas brincadeiras e jogos praticados pelas crianças que se constituiu no processo sócio histórico. Referimo-nos, por exemplo, aos brinquedos como pião, os papagaios de papel, carrinho de rolamento (feito com garrafa pet), barquinhos de papel, a amarelinha, a peteca, cantigas de roda e dentre outros brinquedos e brincadeiras que fazem parte da infância com suas especificidades e significação, vale ressaltar também o "uso da linguagem que se desenvolvem especificamente no âmbito das re- lações de pares e que são distintos dos processos dos adultos" (SARMENTO, 2004, p. 7).

As culturas da infância se designam em duas instâncias, a primeira está ligada as relações sociais consideradas a nível universal, e a segunda instância baseia-se nas relações interpessoais de cada criança e em suas condições sociais, no caso de estruturais e simbólicas, que imbrica na sua produção como ator social. Assim, Sarmento (2004, p. 9), afirma:

\begin{abstract}
Desde logo, na sociologia, onde o conceito de "socialização", com raízes na obra de Emile Durkheim, remeteu para a condição de seres pré-sociais as crianças, assim tematizadas com objeto de um processo de inclusão de valores, normas de comportamento, e de saberes uteis para o exercício futuro de práticas sociais pertinentes.
\end{abstract}

Pelo olhar dessa produção teórica sociológica as crianças eram tidas como objetos manipuláveis, sempre passivas, como peças de dominação do controle social, a desconstrução dessa "socialização" é intrínseco para a emancipação da infância, em percebêlos sujeitos atores da cultura social. Dessa forma, a cultura de pares possibilita as crianças uma maior aproximação do mundo que as rodeia, permitindo-as produzirem, reinventar e criar.

Com relação as suas produções, Santos et al (2007), traz um ponto relevante com relação a autonomia dos aprendizes, que é fundamental eles terem a liberdade de construírem e lerem seus próprios textos. Desse modo, o educador deve garantir, que as crianças se apropriem desde cedo, do sistema de escrita alfabético, desenvolvendo um trabalho sistemático e reflexivo. Também, é necessário que haja "[...] o de- 
senvolvimento de um ensino no nível da palavra, que leve o aluno a perceber que $o$ que a escrita representa (nota no papel) é sua pauta sonora, e não o seu significado, e que o faz através da relação fonema/grafema" (SANTOS et al., 2007, p. 21).

Vale ressaltar que para este processo ser mais significativo na apropriação do sistema alfabético é fundamental que o educador possibilite o aprendiz de refletir acerca das quantidades de letras e sílabas, bem como a ordem e posição das letras, conseguindo perceber a comparação entre as palavras, com relação a quantidade e semelhança de letras e sílabas contidas nas palavras, assim como poder explorar as rimas e os vocábulos que também possuem o mesmo som em distintas maneiras.

Santos et al. (2007, p. 21) afirmam que é fundamental que o educador prese:

Essas atividades de reflexão sobre as palavras que podem estar inseridas na leitura e na produção de textos, uma vez que são muitos os gêneros que favorecem esse trabalho, como os poemas, as parlendas, as cantigas, etc. Por outro lado, o trabalho com palavras estáveis, como os nomes dos alunos, é fundamental, principalmente no início da alfabetização.

Alfabetizar a partir de gêneros textuais possibilita uma maior facilidade em nível de contextualização e entendimento do aprendiz, pois estes gêneros, como cita o autor, traz para o ensino-aprendizagem um trabalho mais significativo, pois eles terão a oportunidade de conhecerem os gêneros e produzirem textos a partir dos exemplos lidos a eles, trazendo para o texto um pouco de seu cotidiano. A criança ficará entusiasmada, vale ressaltar também o quão relevante é de trabalhar a identidade das crian- ças, a partir do significado e construção da escrita e leitura do próprio nome.

Assim, como é importante ressaltar na alfabetização as práticas culturais na infância, seja ela uma brincadeira, cantiga ou lenda folclórica, a partir desse contexto o educador tem variadas possibilidades de desenvolver a escrita e leitura de seus alunos. Possibilitando a criança, construir fantasias e reproduzir o que ela vivencia com seus parceiros ou grupo, estabelecendo fronteiras de inclusão e exclusão, como relação de gênero, status, e faixa etária, que se definem pelas identificações sociais. Portanto:

\begin{abstract}
A interatividade é, deste modo, estratégica, sendo acompanhada de um conjunto de ações táticas que lhe dão sequência e contorno: a identificação com "amigos" dos companheiros de atividades; a defesa do espaço interativo face a crianças exteriores ao seu grupo de amigos; a partilha de rituais, sobretudo baseados em lendas e mitos culturais; a criação de estratégias para evitar fazer o que não querem; a elaboração de ajustes para contornar as regras dos adultos - estes ajustes são respostas inovadoras e coletivas... (SARMENTO, 2004, p. 11).
\end{abstract}

São essas construções que atravessam até as próprias regras estabelecidas pelos adultos, mas que as crianças contornam e exercitam, no seu modelo de grupo e de como percebem a sociedade e mundo. Além dessa interatividade que cita o autor acima, há também a ludicidade que se associa as culturas da infância, mas que não se destina tão somente a essa cultura. Para Rodrigues e Santos (2014, p. 114):

A ludicidade está relacionada com a criatividade, autonomia, liberdade e interação entre as pessoas envolvidas neste processo. É um artificio que os docentes usufruem para a- 
primorar e despertar o gosto pelo conhecimento de seus educandos, de maneira prazerosa e participativa.

Brincar é algo intrínseco do homem, ele não está só atrelado as crianças, mas também aos adultos, entretanto, esse brincar ou participar de um jogo, é uma ação que promove a mediação entre o espaço interior e o mundo objetivo. A distinção que existe entre a brincadeira dos adultos para as crianças, é que a brincadeira e as coisas sérias do ócio são diferentes, a momentos para cada coisa, e para a criança a brincadeira é vista como algo mais sério que elas praticam. (SARMENTO, 2004)

Portanto, alfabetizar tendo a percepção na cultura da infância, é perceber a criança enquanto ator social e cultural, através das suas especificidades, mostrando-se produtora e disseminadora de cultural, deixando mais interessante a apropriação da escrita e leitura permeando a relevância das práticas culturais na infância, como é o exemplo das brincadeiras e jogos que fazem parte do social da infância.

No próximo tópico, será abordado de forma mais concisa sobre as práticas culturais na infância, em específico a peteca, que foi o foco do nosso projeto de estágio supervisionado. Abordando a origem da peteca, seu contexto cultural e social como brincadeira da infância.

\section{A PETECA COMO PRÁTICA CULTURAL NA INFÂNCIA}

Este tópico apresenta a reflexão sobre a peteca enquanto prática cultura na infância, permeando seu contexto histórico e social na construção da brincadeira de infância. Concordando com Lima (2009), o brincar pode ser entendido como uma prática cultural, que estimula o desenvolvimento das crianças, através de atividades. As brincadeiras elas não ficam só explicitas no caráter da motricidade, ela envolve criatividade, raciocínio lógico e vontade de participar e aprender. Assim, como correr é algo necessário aos nossos estímulos físicos, aprender a pensar a partir de uma prática lúdica é algo que faz diferença na vida do aprendiz e/ou aluno.

A peteca constitui um jogo ou brincadeira que explora tanto a interatividade, como movimento, percepção, atenção e atributos mais específicos como: coordenação motora para a confecção/montagem da peteca, apropriação do conceito de regras, do contexto histórico "padrão" do jogo peteca, criatividade para desempenhar e criar brincadeiras, estimula a superar desafios e dentre outros aspectos que podem ser aproveitados a partir dessa prática cultural. (LIMA, 2009)

Para compreender a peteca como prática cultural na infância, é necessário compreender sua conceituação. Segundo Neto (2005), a peteca é um jogo originário do Brasil, em específico das tribos tupis (indígenas) de Minas Gerais.

Considerada a partir de 1985 como esporte oficial, genuinamente brasileiro, a peteca, antes confeccionada em palha de milho, com enchimento de areia ou serragem, e com penas de galinha, hoje aparece padronizada com rodelas de borracha sobrepostas e quatro penas brancas de peru (NETO, 2005, p. 12).

A peteca tem uma base de couro, que é uma bola achatada, onde se enfiam as penas, geralmente feita nas tribos indígenas com palha de milho, que segundo Neto 
(2005, p. 13) "coincide com a colheita de milho e com as festas de Santo Antônio, São José e São Pedro". O autor ainda afirma que o jogo de peteca era usado para treinamento militar, eles acreditavam que esse tipo de jogo poderia melhorar as habilidades físicas dos jogadores.

O jogo de peteca se tornou oficial e de caráter esportivo profissional, onde há competições, que é estabelecido as equipes, juízes, partidas e a peteca.

De origem indígena, este jogo teve sua prática regulamentada, por muitos anos, nos Clubes América e Regatas São Cristóvão do Rio de Janeiro. Conta-se que, em 1928, nas Olimpíadas de Antuérpia, os brasileiros exibiram esse jogo, desconhecido dos europeus, causando-lhes tão boa impressão que foi solicitada, ao médico esportivo Dr. José Maria de Melo Castelo Branco, sua regulamentação. Enviada posteriormente, tornou-se, o jogo, mais difundido na Finlândia do que no Brasil, conforme declaração de atletas, em recente visita ao país (FEITAL et al, 2009, p. 45).

Podemos notar essa prática em qualquer lugar praiano, onde um grupo de pessoas se reúne em círculo, e uma pessoa fica no centro para bater e rebater para os demais, quem deixar cair no chão assume o papel de quem está no centro, o objetivo é mantê-la em trajetórias áreas, sendo batida pela palma da mão. As crianças também as utilizam em suas atividades de passa tempo, geralmente na época de São João. A peteca como brinquedo conhecido, se percebe por sua base mais pesada, ao ser batida já cai no chão com sua base voltada para baixo e as penas (mais leves) para cima. Facilitando ao jogador que ele bata com sua palma da mão. "Jogar peteca é uma brincadeira que tem uma vocação cooperativa, os jogadores evoluem juntos, quanto mais um acerta mais facilita a vida do outro" (BLAUTH, 2013, p. 28).

O desenvolvimento de uma prática cultural, no caso da peteca, além desses itens elaborados, ela possibilita na criança uma aprendizagem simbólica. Essa aprendizagem é aquela que a criança vê um objeto e consegue imaginar outras coisas, como por exemplo, um pedaço de pano ela consiga pensar ou fantasiar que é uma palha de miIho para confeccionar a peteca. Para Lima (2009, p. 5) a função simbólica é:

Toda aprendizagem escolar depende do exercício da função simbólica. Os conhecimentos das várias áreas são organizados em sistemas conceituais que têm na capacidade de simbolizar do ser humano seu eixo principal. Sendo assim, o exercício da função simbólica é essencial desde a educação infantil. Seu desenvolvimento é fundamental, pois estabelece bases para as aprendizagens futuras, incluindo as aprendizagens escolares.

Brincar de peteca, pode ser considerado uma atividade simbólica, pois no entendimento de que ela é uma prática cultural da infância: a criança adquire desenvolvimento a partir das apropriações das práticas culturais, estabelecendo vínculos interpessoais, conhecimento variado deste ato de aprender brincando e também constitui uma identidade e pertencimento, com relação ao coletivo. (LIMA, 2009)

No próximo tópico abordaremos nossa experiência no estágio supervisionado a partir do projeto de intervenção de prática cultural - peteca. Trazendo momentos reflexivos das aulas, atividades e nossa percepção docente frente a essa experiência dinamizadora. 
4 ANÁLISE DIDÁTICA ACERCA DAS CONTRIBUIÇÕES DA PRÁTICA CULTURAL: A PETECA

O projeto de intervenção propôs a alfabetização e letramento de crianças, através de atividades no contexto da brincadeira com a peteca, explorando essa prática lúdica da infância para que ocorresse uma aprendizagem dinamizadora e simbólica. Dialogando com as disciplinas de forma interdisciplinar. Para a análise da proposta de intervenção, usou-se a metodologia: autoestudo, que se focaliza:

[...] na prática pessoal e na experiência dos professores, pode-se abraçar o genuíno questionamento para chegar a um melhor entendimento das complexidades do ensinar e do aprender. Assim, o auto estudo pode ser considerado uma extensão sobre a "reflexão sobre a prática" com aspirações que vão além do desenvolvimento profissional e conduzem à consideração de ideias e a construção e comunicação de um novo conhecimento (SOUZA et al, 2014, p. 299).

O projeto nos possibilitou repensar a alfabetização e de como construir o conhecimento com os aprendizes. No período de observação que antecede o da regência, foi feito um diagnóstico com uma das turmas que ficamos designada, o fundamental I, esse diagnóstico era para identificar o nível dos discentes, se estavam no pré-silábico, silábico ou silábico-alfabético. A partir da análise do diagnóstico fizemos a intervenção de acordo ao ponto de desenvolvimento dos sujeitos.

Escolhemos trabalhar com essa prática cultural, pois é algo que faz parte da infância e que é mais próximo de suas realidades, inserindo-a no contexto dos conteúdos escolares, os discentes apresentam maior desejo de aprender, pois o aspecto lúdico está em ação. Muitos discentes sentem falta de uma metodologia que aborde mais métodos dinamizadores. Alfabetizar a partir de algo que faz parte do cotidiano das crianças, fica mais interessante no processo de desenvolvimento.

A regência foi exercida no período de duas semanas, iremos elencar as reflexões acerca desses momentos significativos para nossa formação acadêmica/profissional, de acordo a cada semana.

\section{- Primeira Semana}

No período de observação identificamos pela sondagem que a turma estava variando entre o nível pré-silábico e silábico, planejamos o incentivo da leitura e a construção de palavras e frases a partir de alguns textos ou informações dialogadas com o conteúdo. Nessa primeira semana, foi trabalhado a história e contexto da peteca, trazendo para os alunos informações, curiosidades, explicando as regras, com isso citavam exemplos que no ambiente familiar e escolar também continha regras e que eles já haviam brincado de peteca.

A partir desse diálogo, as crianças citaram outros jogos que gostavam e que começava com a letra " $P$ ", com isso surgiram: pião, pega-pega, pula-pula, pipa e dentre outras brincadeiras que aproveitamos para que fosse construído essas palavras de acordo com a ajuda deles, no quadro, fomos trabalhar a palavra peteca, eles ditavam como escrevia, alguns vinham, identificavam a letra que começava e terminava a palavra peteca, outros vinham e separava a sílaba dessa palavra e a partir da primeira sílaba, formulavam outras palavras. Elas usavam do método de "bater palmas" para saber a quantidade de sílabas que conti- 
nham cada palavra. Alguns ainda sentiam dificuldade para identificar letras do alfabeto, mas orientávamos e eles procuravam fazer a identificação com outra palavra, analisando a sonoridade das palavras, as vogais e consoantes que continha.

Fotografia 1: Realização de Atividades

Photo 1: Carrying out Activities

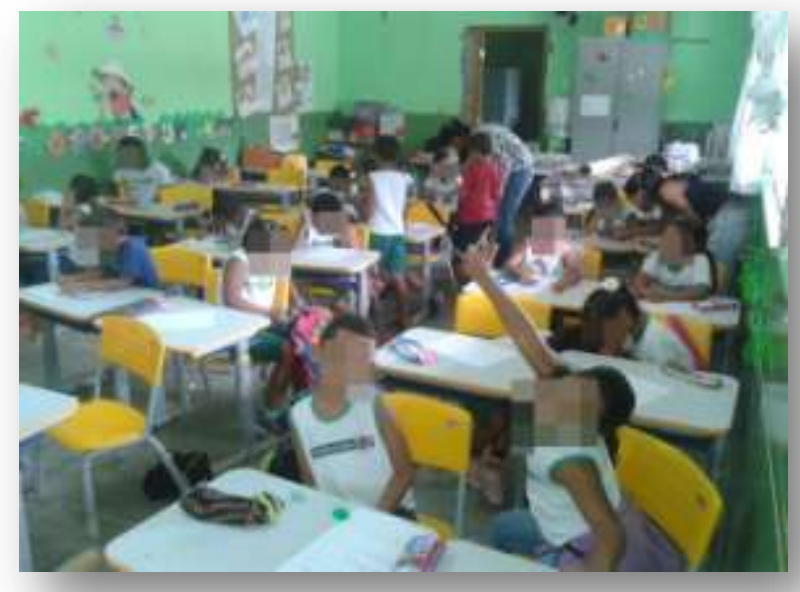

Fonte: Arquivo do estagiário

Fotografia 2: Dialogando sobre a peteca Photo 2: Dialoging on the Shuttlecock

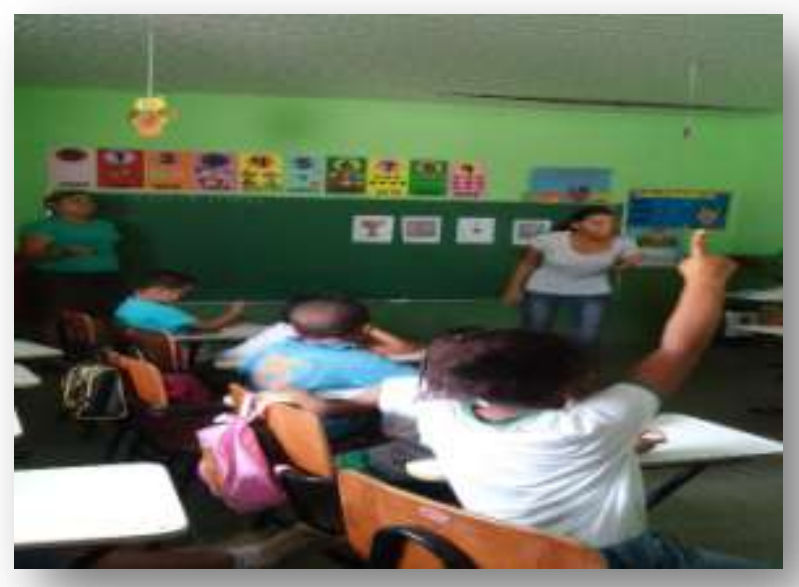

Fonte: Arquivo do estagiário

Ao refletirmos sobre a peteca na apreensão dos conhecimentos da escrita e leitura, abordamos sobre a importância do ato de escrever e ler. A concepção que eles tinham de que precisariam aprender para irem para outra escola, que relataram através do diagnóstico da escrita, que foi aplicado no período de observação, estava sendo problematizada pela importância real desse aprendizado. Ao se trabalhar os textos que continham aspectos de brincadeira que envolvia a peteca, identificávamos com os discentes a estrutura do texto, bem como a interpretação, perguntando o que compreenderam do texto, além de trabalhar a identificação dos aspectos de nome do autor, título, personagens principais e dentre outros. Também exploramos a identificação de unidades menores, quando iniciava e terminava uma palavra, com as atividades, percebíamos quais os alunos apresentavam uma maior dificuldade, resolvemos separar a sala em quatro grupos para que ocorresse a mediação de forma mais precisa.

A partir da contextualização da brincadeira peteca, houve a contextualização da estrutura de um texto que explora uma determinada brincadeira, as crianças foram dialogando entre si e sugerindo como seria esse jogo, definiram o nome da brincadeira, as habilidades, regras, quantas pessoas iriam participar. Relembrando de jogos que se assemelham pelas regras, por este último aspecto, ressaltaram outros jogos que praticam em seu dia a dia, como o futebol e pipa. Alguns discentes, gostavam de ir ao quadro, e sempre quando algum colega ficava na dúvida de como começava alguma palavra havia ajuda e troca de experiência entre em a turma, depois de alguns dias, não estavam mais precisando consultar o alfabeto que era exposto na sala, pois os alunos já tinham essa relação de troca com os colegas. 


\section{- Segunda Semana:}

Na segunda semana, como a escola ainda estava em época de prova e preparação para festa junina, tivemos que adaptar o plano para revisão dos conteúdos. Com relação a Língua Portuguesa, resolvemos optar por trabalhar gêneros textuais, escoIhemos bilhetes para ser contextualizado a estrutura do texto e para que serve. Conversamos com eles, se já haviam recebido algum bilhete, uns disseram que sim, de amiguinhos ou dos pais, antes de iniciarmos a proposta deles construírem os bilhetes, explicamos a estrutura desse gênero textual e chamamos alguns alunos para vir ao quadro escrever o seu bilhete, eles escreviam o nome da pessoa que estava enviando o biIhete e da pessoa que estava recebendo, e de como seria a mensagem. Para aproveitar essa construção ainda era pedido que identificasse algumas sílabas e unidades menores. O bilhete tinha destinatário real, eles endereçavam para os pais ou os coleguinhas da turma.

Fotografia 3: Realização das atividades

Photo 3: Carrying out the activities

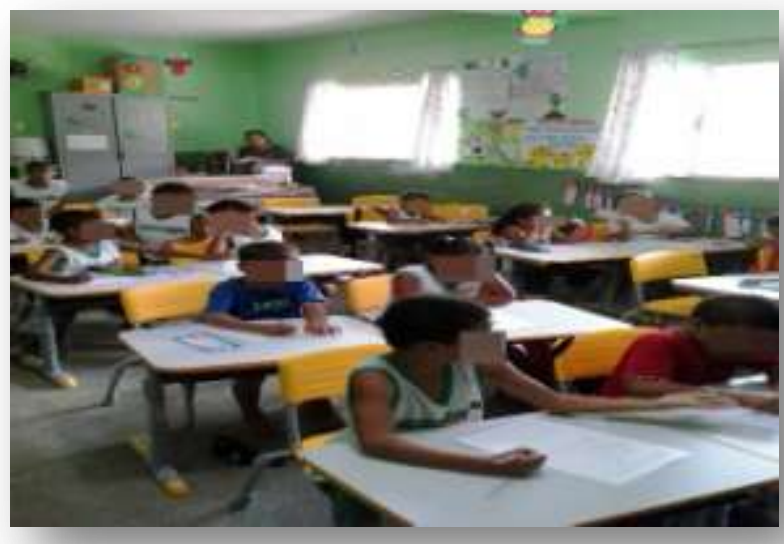

Fonte: Arquivo do estagiário
Fotografia 4: Realização das atividades

Photo 3: Carrying out the activities

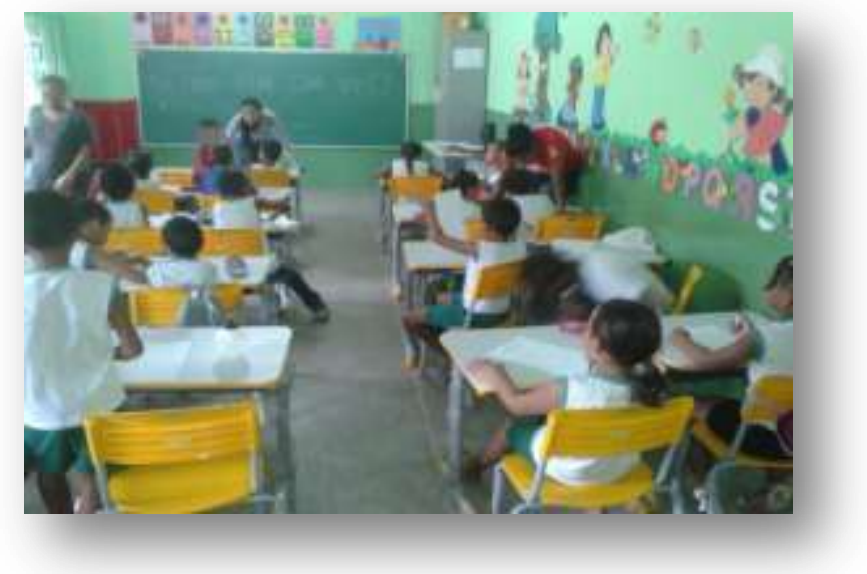

Fonte: Arquivo do estagiário

Propomos que construíssem com nossa ajuda, um bilhete para alguém que eles gostassem muito, convidando para brincar. Eles ficaram empolgados com a proposta e isso fez com que se empenhassem para poder escrever a mensagem. Nessa construção, foi pedido para que eles analisassem a sonoridade da palavra, identificando sílabas, assim ficaria mais fácil para conseguir escrever, eles sabiam a quantidade de vogais que continha nas palavras, e às vezes acabavam confundindo algumas consoantes, por exemplo, C e K em uma palavra.

Como o projeto de prática cultural é interdisciplinar, pudemos trabalhar sobre o jogo da peteca, nas disciplinas de português, matemática, ciências e história, contextualizando na matemática o início das quatro operações, como eles ainda estavam na primeira, pedíamos para somar, mas de acordo a quantidade de sílabas ou figuras. Em uma atividade de interpretação, eles identificavam alguns aspectos do texto, escreviam as palavras que estavam em destaque e separava as sílabas, depois contava a quantidade de sílabas.

No exercício de contextualizar as brinca- 
deiras, fomos construir a peteca com os educandos, essa construção estava explorando a função simbólica, pois os materiais iriam representar uma peteca indígena. Utilizamos tecidos coloridos, sacola, jornal e revista para que eles pudessem explorar a criatividade e imaginação, no ato da construção eles estabeleciam relações de interatividade com os colegas, relembrávamos de como é constituído o jogo de peteca, sua finalidade e dentre outros aspectos, alguns discentes ainda citaram, que o jogo de peteca remetia ao jogo de tênis, eles aproveitaram para brincar e sistematizar todo conhecimento exposto pelo contexto da peteca.

Fotografia 5: Realização das atividades Photo 5: Carrying out the activities

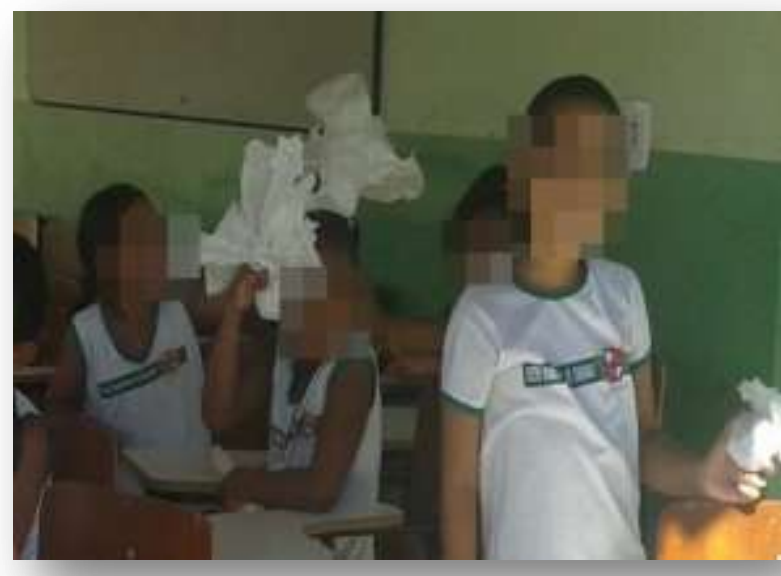

Fonte: Arquivo do estagiário
Fotografia 6: Realização das atividades

Photo 6: Carrying out the activities

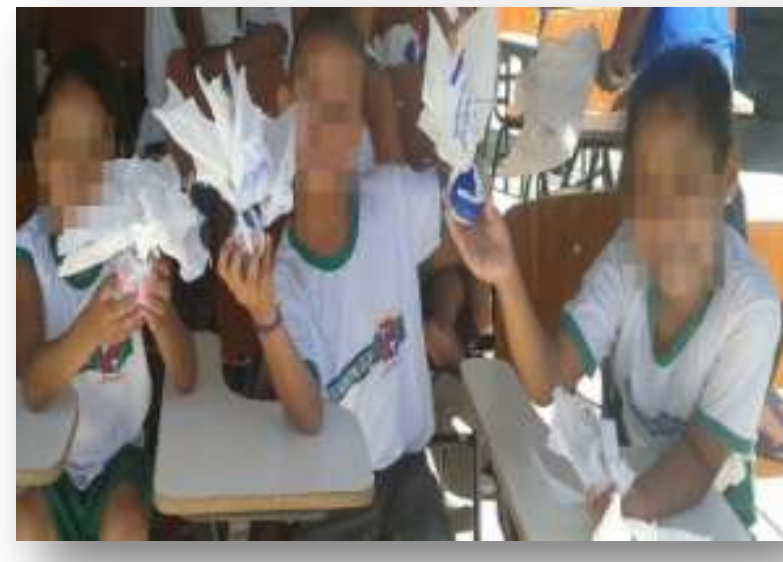

Fonte: Arquivo do estagiário

No finalzinho dessa última semana, pudemos notar o avanço de algumas crianças, uma em específico tinha muita ajuda dos pais em casa, e já estava lendo, mas não tínhamos percebido isso na primeira semana, a partir da segunda ele começou a escrever de forma ordenada e coerente e ler o que escrevia, coisa que os coleguinhas dele ainda não estava fazendo. Entretanto, as demais crianças já tinham a percepção da sonoridade da palavra, de como começava e terminava identificando no texto as sílabas, unidades menores. Dialogando sobre o que entendia do texto de forma precisa, e outros não sentiam mais dificuldade em começar a escrever, se o estágio perdurasse por um mês, o avanço seria ainda maior. Nota-se o quanto relevante se trabaIhar de maneira significativa para os discentes, a partir do que eles já conhecem e convivem, no caso de suas produções culturais infantis, as brincadeiras e jogos.

\section{CONSIDERAÇÕES FINAIS}

Com a experiência dos estágios no curso de Pedagogia, a aproximação do lócus com 
os conhecimentos que estudamos e discutimos, é uma experiência dinamizadora e analítica, pois além de contribuirmos para uma melhor educação, na base infantil, temos a possibilidade de refletirmos sobre como a prática docente deve ser flexível e sistemática.

Alfabetizar a partir de uma prática cultural nos mostrou o quão relevante pode ser essa prática, pois envolve algo que faz parte da infância e será um desenvolvimento contextualizado para as crianças aprenderem a partir de suas próprias produções, se enxergarem como sujeitos atores do processo de aprendizagem. Esse estágio nos proporcionou essa análise de que dá para alfabetizar permeando contextos intrínsecos ao cotidiano do aluno, e de como a prática docente pode ser flexível e dialética em prol de uma melhor educação.

No processo de alfabetização e letramento percebemos, que os discentes sentem mais prazer em aprender quando abordamos exemplos que eles vivenciam, percebem essa contextualização para a forma escrita, percebem os códigos e sinais, pois sentem-se mais seguros, já que a prática da leitura está atrelada a todo momento, eles compreendem que a escrita é um ato de transmitir informação e conhecimento, assim como a fala. Por isso sentimos a necessidade de trazer para esse contexto os mais variados gêneros textuais, para ser trabaIhado a estrutura desses textos, lendo para eles em situações, onde essa leitura faça sentido, fazer com que eles percebam essa importância do porquê ler e escrever.

As culturas infantis possibilitam um amplo desenvolvimento para as crianças, com a mediação elas percebem de como podem ser sujeitos transformadores e atores sociais, que as brincadeiras e jogos são constru- ções que fazem parte da infância, com suas particularidades em cada cultura, região, país e contexto histórico. Isso é perceber a construção do entendimento de homem acerca da produção cultural e de desenvolvimento.

A formação como Pedagoga, só tem enriquecido e trazido uma carga de aprendizagem, experiências e provocações, essas com relação a como melhorar a prática docente, a proposta de intervenção acerca de uma prática cultural da infância, nos fez perceber de como esse processo de alfabetização fica mais dinamizador quando envolve o contexto dos discentes e quanto mais criativo for essa prática, mais significativa será. Portanto, fica evidenciado que o ser educador necessita ser reflexivo diante sua prática e colocar em ação suas modificações para melhoria desse processo.

Esse artigo de experiência traz questões relevantes para pensarmos o ato de alfabetizar, propondo o que podemos contribuir, enriquecer e aprimorar dessa prática cultural, do que mais podemos aproveitar dela para que a alfabetização das crianças seja tida de forma contextualizada e de desejo para elas. Quais os desafios podemos propor? Quais práticas culturais podemos trazer para a nossa metodologia, que através das brincadeiras, promover o conhecimento interligados as áreas de conhecimento? São questões que nos levam a analisar o processo de ensino-aprendizagem e de como podemos aprimorar nossa prática docente.

\section{REFERÊNCIAS}

ABREU, A. R.; ARATANGY, C. R.; MINGUES, E.; DIAS, M. C.; DURANTE, M.; WEISZ, T. (Org.). Alfabetização: livro do professor. Brasília: fundescola/sef-mec, 2000. 
BARBOSA, M. C. S. Culturas infantis: contribuições e reflexões. Curitiba: Rev. Diálogo Educ., v. 14, n. 43, p. 645-667, set./dez. 2014. https://doi.org/10.7213/dialogo.edu c.14.043.DS01

BLAUTH, G. Jardim das brincadeiras: uma estratégia lúdica para a educação ecológica. São Paulo: Ministério da Educação - Neogrid, 2013.

FEITAL, D.; CÔRTES, M. Projeto construindo o futuro da agricultura familiar: reencantando a infância com cantigas, brincadeiras e diversão. Viçosa: centro de tecnologias alternativas CTA - Zona da Mata, 2009. GEIGER, P. (Org.). Calda Aulete - Minidicionário contemporâneo: da língua portuguesa. 3 ed. Rio de Janeiro: Lexikon, 2011. P. 539.

LIMA, E. S. Coleção cultura ciência e cidadania. Prática culturais e aprendizagem: Pipa. São Paulo: Sobradinho, 2009.

NETO, A. F. (Org.). Jogos Indígenas. São Paulo: Indaba Sênior Regional, 2005.

SANTOS, C. F.; MENDONÇA, M. (Org.) Alfabetização e letramento: conceitos e relações. Belo Horizonte: Autêntica, 2007.

SARMENTO, M. J. Imaginário e cultura da infância. Instituto de Estudos da Criança, Universidade de Minho, 2004.

SOUZA, M. I. G. F. M. de; FERNADES, M. A. F. $\mathrm{O}$ autoestudo e as abordagens narrativobiográficas na formação de professores. Educação (Porto Alegre, impresso), v. 37, n. 2, p. 297-306, maio-ago, 2014.

RODRIGUES, A. S.; SANTOS, S. D. de O. Reflexões sobre o estágio na educação infantil: contribuindo para uma prática de ação. Estação Científica (UNIFAP), Macapá, v. 4, n. 1, p. 107-120, jan.-jun. 2014.

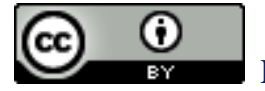
access article distributed under the terms of the Creative Commons Attribution License, which permits unrestricted use, distribution, and reproduction in any medium, provided the original work is properly cited.

Artigo recebido em 03 de janeiro de 2017.

Avaliado em 15 de dezembro de 2017.

Aceito em 16 de janeiro de 2018.

Publicado em 25 de maio de 2018.

\section{Como citar este artigo (ABNT):}

RODRIGUES, Andrêssa Silva; SANTOS, Sânzio Danilo de Oliveira. As práticas culturais de infância no processo de alfabetização e letramento no Ensino Fundamental I. Estação Científica (UNIFAP), Macapá, v. 8, n. 1, p. 67-79, jan./abr. 2018. 